\title{
Association of serum levels of epidermal growth factor with disease severity in patients with unresectable hepatocellular carcinoma
}

\author{
Mohamed Ahmed Samy Kohla ${ }^{1}$, Om Kolsoum Al-Haddad ${ }^{1}$, Ali Nada ${ }^{1}$, \\ Mohamed Al-Warraky ${ }^{2}$, Manar Obada ${ }^{3}$, Mohamed Amer ${ }^{1}$, Sameera Ezzat ${ }^{4}$, \\ Ashraf Abou Gabal ${ }^{1}$ \\ ${ }^{1}$ Department of Hepatology, National Liver Institute, Menoufia University, 32511 Menoufia, Egypt \\ ${ }^{2}$ Department of Radiology, National Liver Institute, Menoufia University, 32511 Menoufia, Egypt \\ ${ }^{3}$ Department of Clinical Biochemistry, National Liver Institute, Menoufia University, 32511 Menoufia, Egypt \\ ${ }^{4}$ Department of Epidemiology, National Liver Institute, Menoufia University, 32511 Menoufia, Egypt
}

\begin{abstract}
Aim: Epidermal growth factor (EGF) is a mitogen for hepatocyte grown in vitro, and its expression is up-regulated during liver regeneration. EGF also plays an important role in tumor initiation and progression. The goal of this study is to assess whether EGF is associated with advanced hepatocellular carcinoma (HCC) and also whether it is a predictive factor of shortened survival. Methods: Serum EGF levels were evaluated in a total of 151 subjects: 51 patients with unresectable HCC, (21 of them were eligible for transarterial chemoembolization (TACE) and serum EGF levels were measured before and 1 week after TACE), 40 patients with chronic hepatitis without cirrhosis, 40 patients with cirrhosis, and 20 healthy controls. Patient demographic and laboratory variables were evaluated as predictive factors of survival in a Cox regression multivariate analysis using SPSS software. Results: The mean serum level of EGF in patients with HCC was $784.49 \mathrm{pg} / \mathrm{mL}$, which was significantly higher $(P<0.05)$ than all other groups. Mean EGF level in cirrhotic patients was $144.69 \mathrm{pg} / \mathrm{mL}$; in those with chronic hepatitis C without cirrhosis, it was $338.64 \mathrm{pg} / \mathrm{mL}$; and in healthy controls, it was $297.15 \mathrm{pg} / \mathrm{mL}$. In group la patients who underwent TACE, the mean serum level of EGF was $759.76 \pm 287.88 \mathrm{pg} / \mathrm{mL}$ before TACE, and $801.14 \pm 276.12 \mathrm{pg} / \mathrm{mL}$ 1 week after treatment $(P=0.34)$. On multivariate Cox regression analysis only age $(P=0.03)$ and higher serum EGF level $(P=0.005)$, were inversely correlated with overall survival. Conclusion: EGF levels were found to be significantly higher in $\mathrm{HCC}$ patients and together with age were the only predictors of poor survival in these patients. There was an increase in EGF levels 1 week after TACE in response to hypoxia; however, this increase was not statistically significant.
\end{abstract}

Key words: Cirrhosis; epidermal growth factor; hepatocellular carcinoma; survival; transarterial chemoembolization

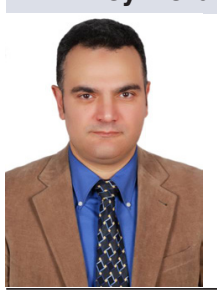

Address for correspondence:

Dr. Mohamed Ahmed Samy Kohla, Department of Hepatology, National Liver Institute, Menoufia University, Yassin Abd El Ghaffar Road, Shebin El-Kom, 32511 Menoufia, Egypt. E-mail: dr_mohamedsamy@yahoo.com

Received: 18-02-2015, Accepted: 14-10-2015

\begin{tabular}{|l|c|}
\hline \multicolumn{2}{|c|}{ Access this article online } \\
\hline \multirow{2}{*}{ Website: } & Quick Response Code \\
\cline { 2 - 2 } http://hrjournal.net & \\
\hline &
\end{tabular}

This is an open access article distributed under the terms of the Creative Commons Attribution-NonCommercial-ShareAlike 3.0 License, which allows others to remix, tweak, and build upon the work non-commercially, as long as the author is credited and the new creations are licensed under the identical terms.

For reprints contact: service@oaepublish.com

How to cite this article: Samy Kohla MA, Al-Haddad OK, Nada A, AlWarraky M, Obada M, Amer M, Ezzat S, Gabal AA. Association of serum levels of epidermal growth factor with disease severity in patients with unresectable hepatocellular carcinoma. Hepatoma Res 2016;2:18-25. 


\section{INTRODUCTION}

Hepatocellular carcinoma (HCC) is the fifth most common cancer and the second leading cause of cancer deaths all over the world according to the World Health Organization data. ${ }^{[1,2]}$ In Egypt, incidences of liver cancer have risen dramatically over the last two decades, and now it is the most common cancer in men and the second most common cancer in women, ${ }^{[3]}$ with an annual rate of HCC development of $1-4 \%$, when hepatitis $\mathrm{C}$ virus (HCV)-related cirrhosis is established. ${ }^{[1]}$ Patients suffering from HCC unlike most solid tumors are confronted with the coexistence of two life-threatening conditions, malignancy and cirrhosis, which makes their prognostic assessments difficult. Despite the usefulness of clinical staging systems for HCC in routine clinical decision making [e.g., Barcelona-Clinic Liver Cancer (BCLC) algorithm], there is still a need to refine and complement outcome predictions. ${ }^{[4]}$

There is an obvious lack of minimally invasive, costeffective, highly sensitive, and specific biomarkers for accurate diagnosis of HCC independent of the cirrhosis status. Alpha-fetoprotein (AFP) is not a reliable marker in early HCC diagnosis due to its low specificity and sensitivity, which renders it unsatisfactory and suggests an urgent need for novel biomarkers for early stage HCC detection. ${ }^{[5]}$ Measurement of circulating levels of angiogenic factors in patients with cancerous tumors have several advantages over the direct assessment of tumor angiogenesis, it does not require a tumor specimen, thus they are theoretically applicable to every cancer patient for their technical simplicity and the availability of repeated measurements during (i) initial diagnosis, (ii) course of various anticancer treatments, and (iii) long after the treatment is over. ${ }^{[6,7]}$ Vascular endothelial growth factor (VEGF) is well known to play a crucial role in tumor angiogenesis by inducing new vessel formation and promoting tumor invasion and metastasis, also VEGF levels are higher in HCC patients. VEGF is used as a biomarker of lymph node metastasis in HCC. In addition, the expression of VEGF is closely correlated with tumor recurrence and prognosis. Of note, VEGF receptor expression levels have also been found to correlate with the development of tumor. ${ }^{[8]}$ Epidermal growth factor (EGF), another key regulator of cell survival and proliferation, is another biomarker identified in the pathogenesis and progression of different types of cancer. ${ }^{[9]}$ During 1980s, several reports described the overexpression of EGF and EGF receptor (EGFR) in a variety of epithelial tumors, which may have a critical role in the etiology of human cancers. ${ }^{[10,11]}$
EGF is also speculated to enhance the transformation of fibroblasts to fibrosarcomas by inducing the development of HCC in transgenic mice. ${ }^{[12]}$ Additionally, a functional polymorphism in the EGF gene is reported to be associated with the risk of development of HCC. ${ }^{[13]}$ Kannangai et al. ${ }^{[14]}$ reported overexpression of EGFR associated with late-stage HCC, increased cell proliferation, and degree of tumor differentiation. All these reports support our hypothesis that EGF is a viable candidate for screening for different cirrhotic populations for early detection of HCC. Transarterial chemoembolization (TACE) being the standard of care treatment for patients with intermediate stage HCC, the best candidates are patients with Child $A^{[1,2]}$ cirrhosis. And, multifocal non-invasive HCC was also included in the study as an arm to determine the EGF levels in response to the treatment. Most importantly, we tried to identify whether circulating EGF levels were altered in cirrhotic livers with and without HCC. The results from the studies showed that EGF was indeed a sensitive biomarker indicative of poor survival outcome, and it was positively correlated with age in the older population.

\section{METHODS}

This case-control study was conducted on 151 patients with chronic liver disease, presented to the Hepatology Clinic, from June 2010 to June 2011. Four groups of patients were studied: HCC, chronic hepatitis $\mathrm{C}$ with or without liver cirrhosis, in addition to a fourth group of healthy control subjects with well-matched age and sex. Group I comprised 51 patients with unresectable HCC (intermediate, advanced, and terminal stages), lesions were assessed regarding the number, size, vascular invasion, and distant metastasis. Patients in this group were subdivided according to eligibility for TACE into two subgroups. Subgroup la comprised 21 patients with an intermediate stage HCC, who were eligible for TACE (BCLC stage B). Their EGF levels were assessed before and 1 week after TACE. Subgroup Ib comprised 30 HCC patients who were not eligible for TACE, in advanced and terminal stages (BCLC stages C and D). Group II comprised 40 chronic hepatitis $C$ patients without cirrhosis. Group III comprised 40 patients with HCV-related cirrhosis with no evidence of HCC. Group IV comprised 20 apparently healthy subjects as a control group with no evidence of liver disease and/or neoplasm. They were all with wellmatched age and sex.

All patients were subjected to the following history taking, complete physical examination, and routine laboratory biochemical and hematological tests. 


\section{Laboratory investigations}

Five milliliter venous blood samples were collected from patients and controls, centrifuged, the serum was separated and divided into two aliquots. The first aliquot was used for routine laboratory investigations including liver function tests (aspartate transaminase, alanine transaminase, bilirubin, and albumin) using fully automated auto analyzer SYNCHRON CX9ALX (Beckman Coulter Inc., CA, USA). Serum AFP concentration was measured using the Automated Chemiluminescence System ACS: 180 provided by Siemens Medical Solutions Diagnostics Corporation, USA. The second aliquot was stored in the deep freezer $\left(-70^{\circ} \mathrm{C}\right)$ for detection of EGF. ${ }^{[15]}$

\section{Serum EGF enzyme-linked immunosorbent assay}

Estimation of serum EGF using Human EGF enzymelinked immunosorbent assay (ELISA) kit (sandwich ELISA), Anogen, catalogue number EL10010 Mississauga, Ontario, Canada (up to $336 \mathrm{pg} / \mathrm{mL}$ ) following manufacturer's protocol.

\section{Radiological examination}

Abdominal ultrasonography, triphsic computed tomography, and dynamic magnetic resonance imaging was performed on patients when required.

\section{TACE}

Chemoembolization was performed percutaneously at the angiography unit of the National Liver Institute with the patient under conscious sedation. After infiltration of local analgesic, the Seldinger technique was used to gain access to the common femoral artery through femoral artery puncture. A 5-french vascular sheath was placed into the common femoral artery over a 0.035 inch guide-wire. Under fluoroscopic guidance, a 5-french glide Cobra catheter (Cordis Corporation, Miami Lakes, Florida, USA) was advanced into the aorta. Angiographic study of the superior mesenteric artery, celiac trunk, and the common hepatic artery was performed to identify all of the vessels feeding the HCC nodule, and to assess patency of the portal vein. In some patients, selective angiography of the phrenic or intercostal arterial branches was required. The arterial branches feeding the tumor were selectively cannulated by microcatheters to proceed with TACE and to ensure better preservation of the surrounding non-tumoral liver tissue. Injection was done using an emulsion of lipiodol-doxorubicin $(50 \mathrm{mg}$ of doxorubicin mixed with 6-20 mL of lipiodol according to tumor size, number, and vascularity to form the emulsion); injection was performed far from the origin of the gastroduodenal, right gastric, and cystic arteries; the amount injected into the tumor was adjusted according to the size and uptake of the tumor. Gel foam was the embolic material injected in all patients.

\section{Follow-up of HCC patients}

Follow-up was conducted for a minimum of 1 year to assess their survival and mortality rates.

\section{Statistical analysis}

Statistically analysis was conducted using SPSS program version 13 for windows (SPSS Inc., Chicago, Illinois, USA) and for all the analysis. A $P<0.05$ was considered statistically significant.

\section{RESULTS}

Most of our patients were males $(92.1 \%$ male, $7.9 \%$ female in group I; $87.5 \%$ male, $12.5 \%$ female in group II; and $85 \%$ male, $15 \%$ female in group III). Mean age for groups I, II, III, and IV was $58.2 \pm 8.7$ [standard deviation(SD)] years, $48.47 \pm 11.51$ years, $49.47 \pm 6.94$ years, and $47.50 \pm$ 6.15 years, respectively, with statistically non-significant difference $(P>0.05)$.

Liver function tests in different patient groups are shown in Table 1. Child-Pugh score and BCLC staging for patients are shown in Tables 2 and 3, respectively.

\section{Radiological criteria of hepatocellular carcinoma}

Twenty-three patients (45.1\%) had a single focal lesion, 9

Table 1: Liver function tests in the three patient groups

\begin{tabular}{lcccc}
\hline & $\begin{array}{c}\text { Group I } \\
(n=51)\end{array}$ & $\begin{array}{c}\text { Group II } \\
(n=40)\end{array}$ & $\begin{array}{c}\text { Group III } \\
(n=40)\end{array}$ & $P$ \\
\hline Bilirubin & $1.76 \pm 1.2$ & $0.83 \pm 0.24$ & $1.72 \pm 1.59$ & $<0.05$ \\
(mg/dL) & & & & \\
Albumin & $3.16 \pm 0.65$ & $4.35 \pm 0.53$ & $3.06 \pm 0.84$ & $<0.05$ \\
(g/dL) & & & & \\
ALT(U/L) & $67.34 \pm 38.4$ & $61.80 \pm 41.13$ & $55.82 \pm 30.17$ & 0.31 \\
AST(U/L) & $90.03 \pm 55.8$ & $48.55 \pm 25.20$ & $67.30 \pm 32.03$ & $<0.05$ \\
Hb(g/dL) & $11.53 \pm 1.86$ & $14.04 \pm 1.78$ & $10.76 \pm 2.31$ & $<0.05$ \\
Platelet & $114.58 \pm 55.0$ & $192.62 \pm 47.9$ & $104.37 \pm 62.9$ & $<0.05$ \\
$\left(/ \mathrm{mm}^{3}\right)$ & & & & \\
\hline
\end{tabular}

Data shown as mean \pm SD. Group I: HCC patients; Group II: chronic hepatitis; Group III: cirrhotic patients; ALT: alanine transferase; AST: aspartate aminotransferase; Hb: hemoglobin; SD: standard deviation; HCC: hepatocellular carcinoma

Table 2: Study of CPS in groups I and II

\begin{tabular}{ccccc}
\hline & CPS (A) (\%) & CPS (B) (\%) & CPS (C) (\%) & $P$ \\
\hline Group I & $24(47)$ & $16(31.3)$ & $11(21.7)$ & $<0.05$ \\
Group II & $19(47.5)$ & $7(17.5)$ & $14(35)$ & \\
\hline
\end{tabular}

CPS: Child-Pugh score; (A): score 5-6; (B): score 7-9; (C): score 10-15; Group I: HCC patients; Group II: chronic hepatitis; HCC: hepatocellular carcinoma

Table 3: BCLC staging in HCC studied patients

\begin{tabular}{lccccc}
\hline Groups & $\begin{array}{c}\text { BCLC (B) } \\
(\%)\end{array}$ & $\begin{array}{c}\text { BCLC (C) } \\
(\%)\end{array}$ & $\begin{array}{c}\text { BCLC (D) } \\
(\%)\end{array}$ & Total & $P$ \\
\hline Group la & $18(85.8)$ & $3(14.3)$ & 0 & 21 & $<0.05$ \\
Group lb & 0 & $13(44)$ & $17(56)$ & 30 & \\
Total & 18 & 16 & 17 & 51 & \\
\hline
\end{tabular}

Group la: HCC, underwent TACE; Group Ib: HCC, did not undergo TACE. BCLC: Barcelona-Clinic Liver Cancer; (B): intermediate stage; (C): advanced stage; (D): end stage; HCC: hepatocellular carcinoma; TACE: transarterial chemoembolization 


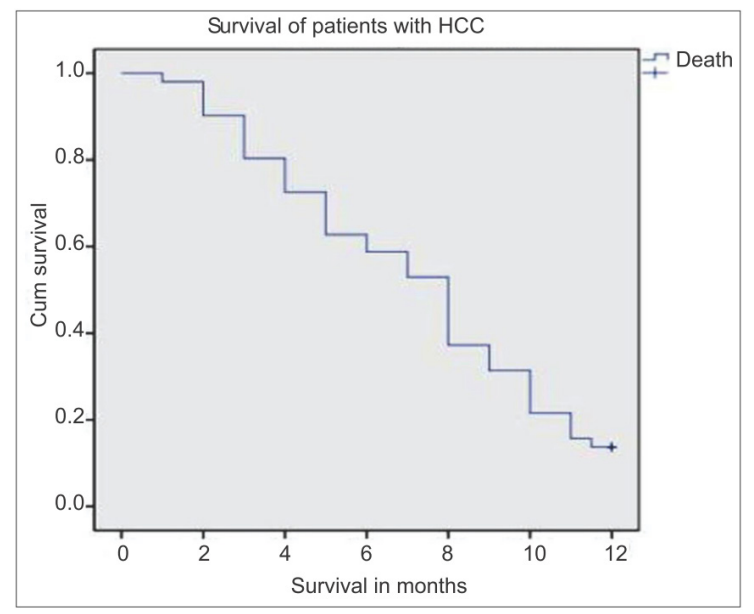

Figure 1: Overall mortality in patients with HCC. HCC: hepatocellular carcinoma

patients (17.6\%) had 2 focal lesions, and 19 (37.3\%) had $\geq 3$ focal lesions. Portal vein thrombosis was present in 12 patients $(23.5 \%)$, while metastasis was detected in 10 patients (19.6\%) [Table 4].

\section{Survival in studied subjects}

Overall mortality in patients with HCC was $86 \%$ at 12 months. Median survival time was 8 months [Figure 1]. Figure 2 is the Kaplan-Meier cumulative survival curve showing the role of serum EGF in patients' disease-related mortality and cumulative survival. Out of 51 patients with HCC, 44 were deceased after 1 year of follow-up, 9 of them died from upper gastrointestinal bleeding, 15 died from sepsis and spontaneous bacterial peritonitis, 5 died of hepatorenal syndrome, 6 patients died at the intensive care unit after an attack of hepatic encephalopathy, 1 patient died from diabetic hypoglycemic, and the exact cause of death could not be identified in 8 patients.

The majority of patients $(85.8 \%)$ of group la were categorized as BCLC stage B, and $14.3 \%$ were in BCLC stage C; while $44 \%$ of group Ib were categorized in BCLC stage $C$ and $17 \%$ were in BCLC stage $D$. In Cox regression analysis, age, and serum EGF level were the only factors significantly predicting poor survival in HCC patients $(P$ $<0.05$ ) [Table 5].

\section{EGF studies in our subjects}

Group I levels were $784.49 \pm 313.25$, group II levels were $338.64 \pm 224.68$, group III levels were $144.69 \pm$ 124.30 , and for group IV, they were $297.15 \pm 175.36 \mathrm{pic} /$ $\mathrm{mL}$. The values are also summarized in Table 6 . In pairwise comparison among individual groups, we found that EGF serum levels were significantly higher in HCC patients compared with the other groups. Statistically significant differences were observed in pair-wise comparison between groups I and II, I and III, I and IV, II and III, and II and IV with $P<0.05$. Groups III and IV

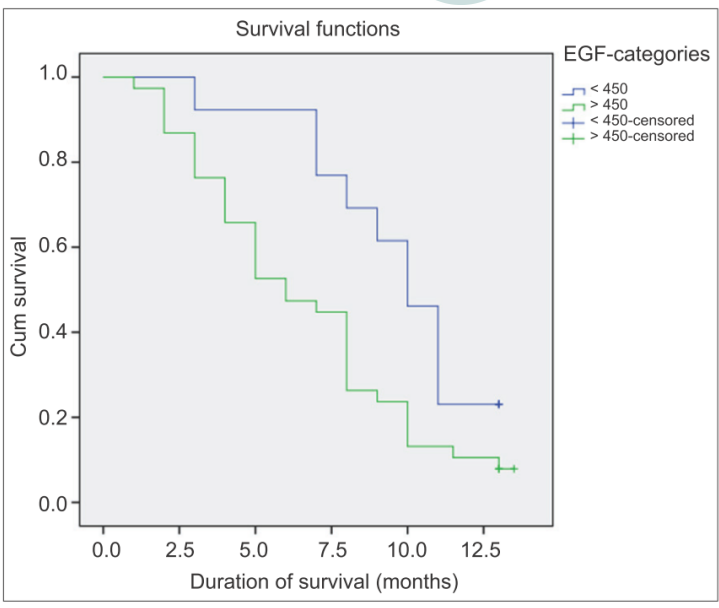

Figure 2: Kaplan-Meier cumulative survival curve showing the role of serum EGF in patients' disease-related mortality and cumulative survival. EGF: epidermal growth factor

Table 4: Radiological criteria of the tumors in HCC patients

\begin{tabular}{|c|c|}
\hline \multicolumn{2}{|l|}{ HCC criteria } \\
\hline Lesion & \\
\hline Single lesion & $23(45.1)$ \\
\hline 2 lesions & $9(17.6)^{\prime}$ \\
\hline$>3$ lesions & 19 (37.3) \\
\hline PVT & \\
\hline With PVT & $12(23.5)$ \\
\hline Without PVT & 39 (76.5) \\
\hline Metastasis & \\
\hline With metastasis & $10(19.6)$ \\
\hline Without metastasis & $41(80.4)$ \\
\hline Lesion size & \\
\hline $\begin{array}{l}\text { Mean } \pm \text { SD in Group la }(\mathrm{cm}) \\
\text { Mean }+ \text { SD in Group }(\mathrm{b}(\mathrm{cm})\end{array}$ & $\begin{array}{l}6.17 \pm 3.055 \\
5.67+1.683\end{array}$ \\
\hline
\end{tabular}

HCC: hepatocellular carcinoma; PVT: portal vein thrombosis; SD: standard deviation

Table 5: Factors affecting survival in patients with HCC

\begin{tabular}{lcc}
\hline & HR $(95 \% \mathrm{Cl})$ & $P$ \\
\hline Age & $1.031(0.984-1.079)$ & 0.03 \\
Sex & $1.324(0.353-4.965)$ & 0.850 \\
Smoking & $1.014(0.893-1.151)$ & 0.490 \\
Pesticide & $1.046(0.851-1.286)$ & 0.206 \\
AFP & $1.000(1.000-1.000)$ & 0.600 \\
EGF & $1.003(1.001-1.004)$ & 0.005 \\
Number of lesions & $0.709(0.478-1.053)$ & 0.705 \\
Lesions size & $1.026(0.890-1.184)$ & 0.066 \\
\hline
\end{tabular}

AFP: alpha-fetoprotein; EGF: epidermal growth factor; HR: hazard ratio; Cl: confidential interval; HCC: hepatocellular carcinoma

showed no significant difference in the EGF levels $(P>$ 0.05) [Table 7]. EGF levels were $766.05 \pm 299.64 \mathrm{pg} /$ $\mathrm{mL}$ in BCLC stage B patients, $738.06 \pm 320.707 \mathrm{pg} / \mathrm{mL}$ in BCLC stage $\mathrm{C}$, and $847.705 \pm 328.70 \mathrm{pg} / \mathrm{mL}$ in BCLC stage $\mathrm{D}$ with no significant difference $(P>0.05)$ [Table 8]. Non-significant difference was found between EGF serum levels in patients with metastatic HCC (mean \pm SD of EGF $847.5 \pm 245.4 \mathrm{pic} / \mathrm{mL}$ ) and in patients with no metastasis (mean \pm SD of EGF $769.1 \pm 328.4$ pic/ $\mathrm{mL})(P>0.05)$ [Table 9]. EGF levels in patients with portal vein thrombosis (mean \pm SD $825.5 \pm 318.04 \mathrm{pic} / \mathrm{mL}$ ) and those without portal vein thrombosis $(772.02 \pm$ $314.89 \mathrm{pic} / \mathrm{mL})(P>0.05)$ [Table 9] were similar. Mean 
EGF level in HCC patients with one focal lesion was 757.1 $\pm 327.8 \mathrm{pic} / \mathrm{mL}$, in those with 2 focal lesions was 873.8 $\pm 334.7 \mathrm{pic} / \mathrm{mL}$, and in those with multiple focal lesions was $775.2 \pm 293.9 \mathrm{pic} / \mathrm{mL}(P<0.05)$ [Table 9]. Serum EGF levels were strongly correlated to the tumor size and serum AFP levels (using Spearman correlation test, with $P<0.05)$.

Analysis of the receiver operating characteristic (ROC) curve of EGF in HCC prediction [Figure 3] revealed that the area under the curve was 0.93 with $95 \%$ confidential interval (CI): $0.89-0.97$. Cut-off value of 450 had $74.5 \%$ sensitivity, and specificity of $84 \%$, while cut-off value of $700 \mathrm{pg} / \mathrm{mL}$ had sensitivity of $60.78 \%$ and specificity of $97 \%$, and cut-off value of 900 had sensitivity $39.22 \%$ and specificity $98 \%$ [Table 10].

Regarding EGF levels in HCC group who underwent TACE (la) although EGF levels were higher after TACE than before, no statistically significant difference was found, mean \pm SD $759.76 \pm 287.88 \mathrm{pic} / \mathrm{mL}$ before TACE, $801.14 \pm 276.12 \mathrm{pic} / \mathrm{mL}$ after TACE with $P<0.05$.

\section{DISCUSSION}

This case-control study was designed to assess the role of EGF as a predictor factor of progression of HCC in terms of correlation with tumor criteria: size, number, vascular

Table 6: Epidermal growth factor serum levels in the four studied groups

\begin{tabular}{lccc}
\hline & $\begin{array}{c}\text { Number of } \\
\text { subjects }\end{array}$ & $\begin{array}{c}\text { EGF serum levels } \\
\text { (mean } \pm \mathrm{SD}, \mathrm{pg} / \mathrm{mL})\end{array}$ & $P$ \\
\hline Group I & 51 & $784.49 \pm 313.25$ & $<0.05$ \\
Group II & 40 & $338.64 \pm 224.68$ & \\
Group III & 40 & $144.69 \pm 124.30$ & \\
Group IV & 20 & $297.15 \pm 175.36$ & \\
Total & 151 & $432.35 \pm 350.35$ & \\
\hline
\end{tabular}

Group I: HCC patients; Group II: chronic hepatitis; Group III: cirrhotic patients; Group IV: healthy control; SD: standard deviation; EGF: epidermal growth factor; HCC: hepatocellular carcinoma

Table 7: Pair-wise comparison of epidermal growth factor between individual groups

\begin{tabular}{lc}
\hline Groups & $P$ \\
\hline Group I vs. II & $<0.05$ \\
Group I vs. III & $<0.05$ \\
Group I vs. IV & $<0.05$ \\
Group II vs. III & $<0.05$ \\
Group II vs. IV & $<0.05$ \\
Group III vs. IV & 0.65 \\
\hline
\end{tabular}

Group I: hepatocellular carcinoma patients; Group II: chronic hepatitis; Group III: cirrhotic patients; Group IV: healthy control

Table 8: Epidermal growth factor levels in HCC patients according to different stages of BCLC classification

\begin{tabular}{lccc}
\hline & $n$ & EGF serum levels (mean \pm SD, pg/mL) & $P$ \\
\hline BCLC (B) & 18 & $766.05 \pm 299.64$ & 0.66 \\
BCLC (C) & 16 & $738.06 \pm 320.707$ & \\
BCLC (D) & 17 & $847.705 \pm 328.70$ & \\
Total & 51 & $784.49 \pm 313.25$ & \\
\hline
\end{tabular}

BCLC: Barcelona-Clinic Liver Cancer; (B): intermediate stage; (C): advanced stage; (D): end stage; SD: standard deviation; EGF: epidermal growth factor; HCC: hepatocellular carcinoma invasions, and patient survival. Subjects of our study were selected from the Hepatology Clinics, National Liver Institute, Menoufia University in the period from June 2010 to June 2011. Four groups of patients were studied: Group I comprised 51 patients with unresectable HCC (which were further subdivided according to the eligibility for TACE into subgroups la and Ib), group II comprised 40 chronic hepatitis $C$ patients, and group III comprised 40 cirrhosis patients. A fourth group of 20 healthy control subjects (age and sex-matched), was also included in the study. HCC patients were followed up for 1 year for evaluation of their 1-year survival rates.

In this study, $45 \%$ of our patients had a single tumor, while $17.6 \%$ had 2 lesions, and $37.3 \%$ had $>3$ lesions. Similar results were presented by Shaker et al. ${ }^{[16]}$ who showed that $38.6 \%$ of their cohort had more than one hepatic focal lesion. Vascular invasion was found in $23.5 \%$ in our HCC patients. These results are not congruous

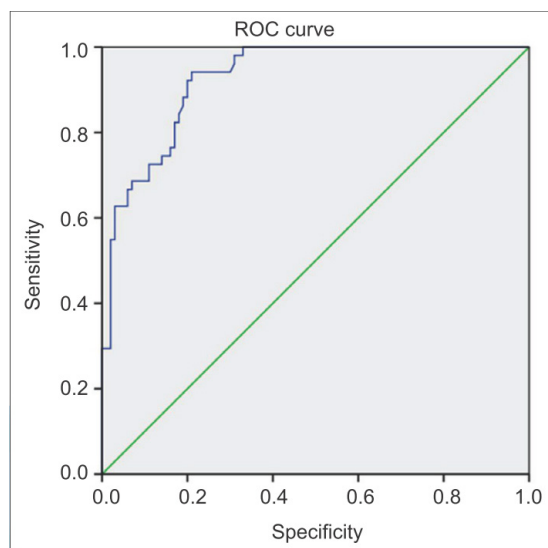

Figure 3: ROC curve of epidermal growth factor value in prediction of hepatocellular carcinoma development. Diagonal segments are produced by ties. ROC: receiver operating characteristic

Table 9: Epidermal growth factor level in HCC patients according to tumor metastases, portal vein thrombosis and number of lesions

\begin{tabular}{lcc}
\hline Serum level of EGF & $\begin{array}{c}\text { EGF serum levels } \\
\text { (mean } \pm \mathrm{SD}, \mathrm{pg} / \mathrm{mL})\end{array}$ & $\boldsymbol{P}$ \\
\hline Non-metastatic tumors & $769.1 \pm 328.4$ & 0.39 \\
Metastatic tumors & $847.5 \pm 245.4$ & \\
No PVT & $772.02 \pm 314.89$ & 0.60 \\
PVT & $825.5 \pm 318.04$ & \\
One lesion $(n=23)$ & $757.1 \pm 327.8$ & 0.64 \\
Two lesions $(n=9)$ & $873.8 \pm 334.7$ & \\
$\geq 3$ lesions $(n=19)$ & $775.2 \pm 293.9$ & \\
\hline
\end{tabular}

EGF: epidermal growth factor; PVT: portal vein thrombosis; SD: standard deviation; EGF: epidermal growth factor; HCC: hepatocellular carcinoma

Table 10: Sensitivity and specificity of epidermal growth factor in HCC group

\begin{tabular}{lcccc}
\hline $\begin{array}{l}\text { Studied } \\
\text { variable }\end{array}$ & $\begin{array}{c}\text { Sensitivity } \\
(\%)\end{array}$ & $\begin{array}{c}\text { Specificity } \\
(\%)\end{array}$ & $\begin{array}{c}\text { PPV } \\
(\%)\end{array}$ & $\begin{array}{c}\text { NPV } \\
(\%)\end{array}$ \\
\hline EGF at the cut-off & 74.5 & 84 & 70.37 & 86.60 \\
value of 450 & & & & \\
Cut-off level 700 & 60.78 & 97 & 91.98 & 82.91 \\
Cut-off level 900 & 39.22 & 98 & 90.91 & 75.97 \\
\hline
\end{tabular}

EGF: epidermal growth factor; PPV: positive predictive value; NPV: negative predictive value; HCC: hepatocellular carcinoma 
with the results of Pirisi et al ${ }^{[17]}$ which showed that the portal vein thrombosis represented $44 \%$ in an autopsied HCC specimen. Another study done by Abdel-Wahab et al. ${ }^{[18]}$ documented that only $15.9 \%$ had portal vein thrombosis. This wide range of discrepancy is attributed to the heterogeneity of the studies (some studies evaluated vascular invasion based on histology while others evaluated it based only on imaging). Follow-up of our HCC patients for 1 year revealed that the overall 1-year mortality was $86 \%$ with a median survival time of 8 months. Altekruse et al. ${ }^{[19]}$ reported a median survival of $<5$ months although a study in Italy found median survival in an untreated group as 10 months, ${ }^{[20]}$ this could be explained by the fact that the majority of HCC patients had more advanced liver disease.

Evaluation of serum levels of EGF in the four groups revealed significantly higher levels of EGF in HCC patients $(784.49 \pm 313.25 \mathrm{pg} / \mathrm{mL})$ compared to the other three non-HCC groups. These results signified the role of EGF in tumor growth and progression. Shehata et al. ${ }^{[21]}$ showed higher EGF and transforming growth factor beta 1 levels in patients with HCC compared to the non-HCC counterparts with HCV viral infection and the control subjects. In our study, age and serum EGF levels were the only factors that significantly predicted survival in our HCC patients; higher EGF levels may be associated with tumor aggressiveness and shortened survival. This hypothesis is supported by the in vitro findings of Klocke et al. ${ }^{[2]}$ who demonstrated that the Ig EGF (secreted variant of human EGF) imparts immortality to hepatocyte in vitro. This also was reported by Inoue et al. ${ }^{[23]}$ who studied vandetanib, an inhibitor of VEGF receptor-2 and EGF receptor, in liver cancer in mice and found that it suppressed tumor development and improved prognosis of liver cancer, improved survival, and reduced number of intrahepatic metastases. Yoneda et al. ${ }^{[24]}$ found that higher levels of EGF were associated with activation of EGF-EGFR pathway associated with the development of CK19-positive HCC, and the EGF-induced increase in growth abilities of HCC may account for the poor prognosis of those patients. DeCicco et al. ${ }^{[25]}$ reported overexpression of EGF receptors (EGFR) in hepatoma cells of rats, suggesting that EGFR may be useful as a dynamic marker for the development of hepatoma. This was confirmed by Sung et al. ${ }^{[26]}$ who concluded that serum EGFR level was a potential biomarker of liver cancer. Kannangai et al.$^{[14]}$ added that EGFR can be considered as a marker for predicting the metastasis and recurrence of HCC. Wu et al. ${ }^{[27]}$ found that EGF was a promoting factor for hepatoma cells stressing on the critical role in EGFinduced proliferation. Wu et al. ${ }^{[28]}$ demonstrated that overexpression of epidermal growth factor-like domain
7 was found predominantly in hepatoma cells and closely correlated with poor prognosis.

ROC curve analysis of EGF in HCC showed that the area under the ROC curve of EGF for the prediction of HCC progression was 0.93 with $95 \% \mathrm{Cl}: 0.89-0.97$. Cut-off value of 450 had $80 \%$ sensitivity while cut-off value of 700 had sensitivity $60.78 \%$ and specificity $97 \%$ while cut-off value of 900 had sensitivity $39.22 \%$ and specificity $98 \%$. Shehata et al. ${ }^{[21]}$ showed that significant higher serum levels of EGF in patients with HCC compared to their levels in patients with $\mathrm{HCV}$ infection and control subjects with cut-off value of $914 \mathrm{pg} / \mathrm{mL}$, EGF shows 63.3\% sensitivity, and $87.5 \%$ specificity for HCC patients.

Our results revealed that the EGF serum level increased slightly in chronic hepatitis activity than levels in established cirrhotic group, reflecting potential role of EGF in fibrosis process as described by other reports such as Iagoda et al., ${ }^{[29]}$ who studied the growth factors and the histological picture of the liver in chronic viral hepatitis and hepatic cirrhosis and found that EGF levels decreased with increase in histological activity and the degree of hepatic fibrosis to cirrhosis. Predictive factors for progressive HCC in our patients were analyzed by binary logistic regression, serum EGF level was found to be a predictive factor of HCC progression. These results agree with the results of a meta-analysis of eight studies concluding that EGF polymorphism is a risk factor in hepatocarcinogenesis. ${ }^{[30]}$ Tanabe et al. ${ }^{[31]}$ stated that in a dose-dependent fashion EGF measurements in serum and in liver tissue were presumed to be most relevant to hepatocyte transformation in cirrhosis and concluded that the EGF gene polymorphism was associated with development of HCC in liver cirrhosis through modulation of EGF levels. Regarding factors affecting patients' survival using Cox regression analysis, older age and higher serum EGF levels were the only factors significantly affecting survival $(P<0.05)$.

Overall, there was a strong correlation $(P<0.05)$ between EGF level and tumor size, signifying its potential role in tumor proliferation and its use as a predictive factor of HCC progression. A major limitation of our study is the relatively small number of patients who underwent TACE, heterogeneity of the study cohort is a limitation in many of the TACE studies because of the wide spectrum of HCC patients eligible for TACE compared with the other modalities of treatment of HCC, this can be overcome by conducting future prospective studies on larger number of patients with similar disease. Interestingly, serum EGF levels were higher post-TACE, although this difference was not statistically significant. The explanation of 
this marginal increase is not yet known, TACE-induced hypoxia (and angiogenesis) might be a contributing factor which needs further studies. The time point to measure serum EGF (1 week after TACE) was chosen at random as an initial evaluation to also address the effect of TACE on EGF, future studies focusing on including 2 additional time points at 1 and 3 months are warranted. Philip et al. ${ }^{[32]}$ tested five EGFR inhibitors: Erlotinib, gefitinib, cetuximab, lapatinib, and vandetanib. Erlotinib showed activity in a phase II study with mixed HCC populations with a median survival of 13 months, and it was being tested in combination with sorafenib in phase III. The other drugs either have not shown meaningful signals of efficacy in phase II, such as gefitinib and lapatinib, or are still in early stages of investigation. ${ }^{[33]}$ Gefinitib, a selective EGFR tyrosine kinase inhibitor, is reported to successfully treat lung cancer. When investigating the effects of gefitinib on tumor-induced angiogenesis, it was found that production of both VEGF and chemokine factor by EGF-stimulated HCC was more markedly inhibited by gefitinib. Sogawa et al. ${ }^{[34]}$ in their study used a novel human monoclonal antibody against EGFR as an imaging probe for $\mathrm{HCC}$ concluded that the radiolabeled human anti-EGFR monoclonal antibody 048-006 has the potential to be a safer imaging probe for predicting tumor uptake of anti-EGFR antibody therapeutic agents in HCC. Studying EGF and its receptors: pathway, therapies, and pipeline concluded that the exploitation of EGFR-directed therapies offered an improvement in survival and quality of life in non-small cell lung cancer and colorectal carcinoma. ${ }^{[3]}$ Additional efforts should be exerted directing further studies on EGFR-directed therapies to the poorly treated HCC patients.

In conclusion, serum EGF levels were found to be significantly higher in HCC group in comparison with cirrhosis, chronic hepatitis, and control groups. A serum level of EGF is a predictor factor of HCC progression and together with older age were the only two predictive factors for poor survival in patients with HCC after 1 year of follow-up. There was an increase of serum EGF levels in response to TACE without significant difference. Future studies should be conducted to focus on EGFR and their inhibitors as new promising therapeutic agents for HCC with the inclusion of more patients with respectable tumors amenable to resection, ablation, and/or liver transplantation who are expected to survive long enough to study any potential prognostic importance of EGF.

\section{Financial support and sponsorship}

This study was supported by the Hepatology and Interventional Radiology Departments at the National
Liver Institute, Menoufiya University, Egypt.

\section{Conflicts of interest}

There are no conflicts of interest.

\section{REFERENCES}

1. El-Serag HB. Hepatocellular carcinoma. N Engl J Med 2011;365:1118-27.

2. Bruix J, Sherman M; Practice Guidelines Committee, American Association for the Study of Liver Diseases. Management of hepatocellular carcinoma. Hepatology 2005;42:1208-36.

3. Ibrahim AS, Khaled HM, Mikhail NN, Baraka H, Kamel H. Cancer incidence in Egypt: results of the national population-based cancer registry program. J Cancer Epidemiol 2014;2014:437971.

4. Villanueva A, Hoshida Y, Toffanin S, Lachenmayer A, Alsinet C, Savic R, Cornella H, Llovet JM. New strategies in hepatocellular carcinoma: genomic prognostic markers. Clin Cancer Res 2010;16:4688-94.

5. Teofănescu I, Gologan E, Stefănescu G, Bălan G. Surveillance of cirrhosis for hepatocellular carcinoma-clinical validation of new serological biomarkers for improved diagnosis. Rev Med Chir Soc Med Nat Iasi 2010;114:39-46. (article in Romanian)

6. Zhu AX, Abrams TA, Miksad R, Blaszkowsky LS, Meyerhardt JA, Zheng H, Muzikansky A, Clark JW, Kwak EL, Schrag D, Jors KR, Fuchs CS, Iafrate AJ, Borger DR, Ryan DP. Phase 1/2 study of everolimus in advanced hepatocellular carcinoma. Cancer 2011;117:5094-102.

7. Carmeliet P, Jain RK. Molecular mechanisms and clinical applications of angiogenesis. Nature 2011;473:298-307.

8. Zhang L, Wang JN, Tang JM, Kong X, Yang JY, Zheng F, Guo LY, Huang YZ, Zhang L, Tian L, Cao SF, Tuo CH, Guo HL, Chen SY. VEGF is essential for the growth and migration of human hepatocellular carcinoma cells. Mol Biol Rep 2012;39:5085-93.

9. González L, Díaz ME, Miquet JG, Sotelo AI, Fernández D, Dominici FP, Bartke A, Turyn D. GH modulates hepatic epidermal growth factor signaling in the mouse. J Endocrinol 2010;204:299-309.

10. Libermann TA, Razon N, Bartal AD, Yarden Y, Schlessinger J, Soreq H. Expression of epidermal growth factor receptors in human brain tumors. Cancer Res 1984;44:753-60.

11. Weichselbaum RR, Dunphy EJ, Beckett MA, Tybor AG, Moran WJ, Goldman ME, Vokes EE, Panje WR. Epidermal growth factor receptor gene amplification and expression in head and neck cancer cell lines. Head Neck 1989;11:437-42.

12. Borlak J, Meier T, Halter R, Spanel R, Spanel-Borowski K. Epidermal growth factor-induced hepatocellular carcinoma: gene expression profiles in precursor lesions, early stage and solitary tumours. Oncogene 2005;24:1809-19.

13. Lee JS, Thorgeirsson SS. Comparative and integrative functional genomics of HCC. Oncogene 2006;25:3801-9.

14. Kannangai R, Sahin F, Torbenson MS. EGFR is phosphorylated at Ty845 in hepatocellular carcinoma. Mod Pathol 2006;19:1456-61.

15. Mroczkowski B, Reich M. Identification of biologically active epidermal growth factor precursor in human fluids and secretions. Endocrinology 1993;132:417-25.

16. Shaker MK, Abdella HM, Khalifa MO, El Dorry AK. Epidemiological characteristics of hepatocellular carcinoma in Egypt: a retrospective analysis of 1313 cases. Liver Int 2013;33:1601-6.

17. Pirisi M, Avellini C, Fabris C, Scott C, Bardus P, Soardo G, Beltrami $\mathrm{CA}$, Bartoli E. Portal vein thrombosis in hepatocellular carcinoma: age and sex distribution in an autopsy study. J Cancer Res Clin Oncol 1998;124:397-400.

18. Abdel-Wahab M, El-Ghawalby N, Mostafa M, Sultan A, El-Sadany M, Fathy O, Salah T, Ezzat F. Epidemiology of hepatocellular carcinoma in lower Egypt, Mansoura Gastroenterology Center. Hepatogastroenterology 2007;54:157-62.

19. Altekruse SF, McGlynn KA, Reichman ME. Hepatocellular carcinoma incidence, mortality, and survival trends in the United States from 1975 to 2005. J Clin Oncol 2009;27:1485-91.

20. Lerose R, Molinari R, Rocchi E, Manenti F, Villa E. Prognostic 
features and survival of hepatocellular carcinoma in Italy: impact of stage of disease. Eur J Cancer 2001;37:239-45.

21. Shehata F, Abdel Monem N, Sakr M, Kasem S, Balbaa M. Epidermal growth factor, its receptor and transforming growth factor- $\beta 1$ in the diagnosis of HCV-induced hepatocellular carcinoma. Med Oncol 2013;30:673

22. Klocke R, Gómez-Lechón MJ, Ehrhardt A, Mendoza-Figueroa T, Donato MT, López-Revilla R, Castell JV, Paul D. Establishment and characterization of immortal hepatocytes derived from various transgenic mouse lines. Biochem Biophys Res Commun 2002;294:86471.

23. Inoue $\mathrm{K}$, Torimura $\mathrm{T}$, Nakamura $\mathrm{T}$, Iwamoto $\mathrm{H}$, Masuda $\mathrm{H}$, Abe $\mathrm{M}$, Hashimoto O, Koga H, Ueno T, Yano H, Sata M. Vandetanib, an inhibitor of VEGF receptor-2 and EGF receptor, suppresses tumor development and improves prognosis of liver cancer in mice. Clin Cancer Res 2012;18:3924-33.

24. Yoneda N, Sato Y, Kitao A, Ikeda H, Sawada-Kitamura S, Miyakoshi M, Harada K, Sasaki M, Matsui O, Nakanuma Y. Epidermal growth factor induces cytokeratin 19 expression accompanied by increased growth abilities in human hepatocellular carcinoma. Lab Invest 2011;91:262-72.

25. DeCicco LA, Kong J, Ringer DP. Carcinogen-induced alteration in liver epidermal growth factor receptor distribution during the promotion stage of hepatocarcinogenesis in rat. Cancer Lett 1997;111:149-56.

26. Sung TI, Wang YJ, Chen CY, Hung TL, Guo HR. Increased serum level of epidermal growth factor receptor in liver cancer patients and its association with exposure to arsenic. Sci Total Environ 2012;424:74-8.

27. Wu BW, Wu Y, Wang JL, Lin JS, Yuan SY, Li A, Cui WR. Study on the mechanism of epidermal growth factor-induced proliferation of hepatoma cells. World J Gastroenterol 2003;9:271-5.

28. Wu F, Yang LY, Li YF, Ou DP, Chen DP, Fan C. Novel role for epidermal growth factor-like domain 7 in metastasis of human hepatocellular carcinoma. Hepatology 2009;50:1839-50.

29. Iagoda AB, Korǒ PV, Geǐvandova NI, Nikitina OA, Kastornaia IV. Growth factors and the hystologic picture of the liver in chronic viral hepatitis and hepatic cirrhosis. Klin Med (Mosk) 2006;84:44-7. (article in Russian)

30. Zhong JH, You XM, Gong WF, Ma L, Zhang Y, Mo QG, Wu LC, Xiao J, Li LQ. Epidermal growth factor gene polymorphism and risk of hepatocellular carcinoma: a meta-analysis. PLoS One 2012;7:e32159.

31. Tanabe KK, Lemoine A, Finkelstein DM, Kawasaki H, Fujii T, Chung RT, Lauwers GY, Kulu Y, Muzikansky A, Kuruppu D, Lanuti M, Goodwin JM, Azoulay D, Fuchs BC. Epidermal growth factor gene functional polymorphism and the risk of hepatocellular carcinoma in patients with cirrhosis. JAMA 2008;299:53-60.

32. Philip PA, Mahoney MR, Allmer C, Thomas J, Pitot HC, Kim G, Donehower RC, Fitch T, Picus J, Erlichman C. Phase II study of Erlotinib (OSI-774) in patients with advanced hepatocellular cancer. $J$ Clin Oncol 2005;23:6657-63.

33. Bekaii-Saab T, Markowitz J, Prescott N, Sadee W, Heerema N, Wei L, Dai Z, Papp A, Campbell A, Culler K, Balint C, O'Neil B, Lee RM, Zalupski M, Dancey J, Chen H, Grever M, Eng C, Villalona-Calero M. A multi-institutional phase II study of the efficacy and tolerability of lapatinib in patients with advanced hepatocellular carcinomas. Clin Cancer Res 2009;15:5895-901.

34. Sogawa C, Tsuji AB, Yoshida C, Inubushi M, Furukawa T, Koizumi M, Akahori Y, Ukai Y, Kurosawa G, Kurosawa Y, Saga T. Novel human monoclonal antibody against epidermal growth factor receptor as an imaging probe for hepatocellular carcinoma. Nucl Med Commun 2012;33:719-25

35. Goffin JR, Zbuk K. Epidermal growth factor receptor: pathway, therapies, and pipeline. Clin Ther 2013;35:1282-303. 